\title{
Space Charge Behavior in Thick Oil-impregnated Pressboard Under HVDC Stresses
}

\author{
Miao Hao, Yuan Zhou, George Chen \\ Electronics \& Electrical Engineering \\ University of Southampton \\ SO17 1BJ UK \\ Gordon Wilson and Paul Jarman \\ National Grid \\ Warwick, UK
}

\begin{abstract}
The space charge accumulation can affect the dielectric performance of oilimpregnated pressboard in convertor transformers. In this paper, the space charge behaviour in $1 \mathrm{~mm}$ thick impregnated pressboards is investigated by the means of pulsed electroacoustic method. The dried pressboards are separately impregnated in fresh oil and service aged oil as comparison. The space charge distributions are investigated under $\pm 15 \mathrm{kV} / \mathrm{mm}$ and $\pm 25 \mathrm{kV} / \mathrm{mm}$ at room temperature. The homocharge injection can be observed for all the samples, which is much more significant in the aged oil impregnated samples. The amount of injected charges and the depth of the injected charges accumulation in the pressboard bulk are closely related to the oil properties, amplitude and polarity of the applied voltages. The service aged oil shows the dominant effects on the local electric field distortion, about $48 \%$ enhanced in the aged oil impregnated samples while about $15 \%$ enhanced in the fresh oil impregnated samples. The estimations of the apparent charge mobility and trap depth also indicate the great impacts caused by the service aged oil.
\end{abstract}

Index Terms - Oil-pressboard, oil aging, space charge, PEA, HVDC, convertor transformer, electric field distortion.

\section{INTRODUCTION}

OIL-PAPER-PRESSBOARD insulation system has been widely applied in electrical industry for very long time and now it is still the main insulation for HVDC equipment, such as convertor transformers. Its dielectric properties are not only affected by the combined stress of electrical, thermal, mechanical and chemical stresses, but also closely related with space charge phenomena [1]. It is well known that space charge accumulation is much easier and more obviously under dc stress, which can result in the distortion of electric field distribution in the dielectric bulk. The localized enhanced electric field can potentially accelerate the degradation of the dielectric material, and even lead to breakdown [2,3]. Therefore, the research on space charge behavior of oil-paper insulation plays a significant role in improving insulation performance and the reliability of HVDC equipment.

In the past few years, space charge dynamics in the oilimpregnated paper insulation have been investigated by the means of the pulsed electroacoustic (PEA) technique [4-8].

Manuscript received on 21 January 2014, in final form 19 June 2014, accepted 6 August 2014
The space charge dynamics in oil-impregnated papers under different environmental conditions, e.g. temperature, moisture, applied voltages as well as thermally aging status was studied. However, these studies are mainly focus on the thin Kraft paper due to the large acoustic attenuation in oil-paper insulation. Therefore, the space charge behavior is significantly affected by the interfacial effects. However, thick pressboards are widely used in convertor transformers, the space charge behavior in the pressboard and its interface with oil needs to be studied. The space charge behaviour in the $1 \mathrm{~mm}$ thick impregnated pressboard has been studied in [9] by using pressure wave propagation (PWP) technique, but the results are not very satisfactory at that time due to the complicated property of oil-impregnated pressboard insulation and the limits of experiment equipment.

In the present paper, the PEA technique has been used to investigate space charge dynamics in the oil-impregnated pressboard with a thickness of $1 \mathrm{~mm}$ under different dc stresses at the room temperature. The space charge behaviors under the volts-on, volts-off and decay conditions are discussed. The effects of oil status on charge dynamics have been studied. The total charge amount and the distortion of the electric field caused by the presence of space charge are also analyzed. 


\section{EXPERIMENTAL SETUP}

The samples used in the study were made of two types of transformer oil (fresh oil and service aged oil), and transformer pressboards impregnated with two types of transformer oil. The type of the fresh oil is Shell Diala ZX-I, which has high oxidation stability and low sulphur content to meet IEC 60296.

Table 1. Status of the oil properties.

\begin{tabular}{|c|c|c|}
\hline & Fresh oil & Aged oil \\
\hline $\begin{array}{c}\text { Moisture (ppm) } \\
\text { Resistivity }(\mathrm{T} \Omega \mathrm{m}) \\
\text { Relative Permittivity } \\
\text { Description }\end{array}$ & $\begin{array}{c}10 \\
7 \\
2.2 \\
\text { transparent }\end{array}$ & $\begin{array}{c}25 \\
0.1 \\
2.6 \\
\text { dark brown } \\
\text { with sludge }\end{array}$ \\
\hline
\end{tabular}

On the other hand, the service aged oil was supplied by National Grid UK showing dark brown color with a small amount of sludge. The status of the two types of oil is shown in the Table 1. The result of UV/Vis spectra (shown in Figure 1) also indicates the differences between these two types of oil. The absorption edge of the aged oil shifts from ultraviolet to visible wavelengths comparing with the fresh oil.

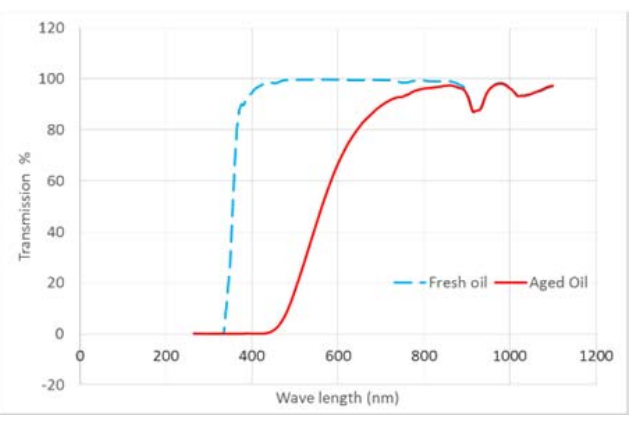

Figure 1. UV/Vis spectra results for two types of oil.

The pressboards used in this paper were the generally available transformer pressboards supplied by Weidmann electrical with a thickness of $1 \mathrm{~mm}$. The pressboards were cut into circular with a diameter of $9 \mathrm{~cm}$, and then dried at $80{ }^{\circ} \mathrm{C}$ for 3 days in a vacuum oven. After that, the dried pressboards were separately impregnated in the two types of oil under $10 \mathrm{~Pa} / 60{ }^{\circ} \mathrm{C}$ for 3 days, which makes the pressboards fully impregnated with oil. The unused impregnated pressboards were kept in a seal container under vacuum condition to avoid absorbing moisture.

In the present study, a purpose built PEA system was installed to overcome the large attenuation caused by the thick sample. A $0.8 \mathrm{~cm}^{2}$ in area PVDF film with a thickness of 40 $\mu \mathrm{m}$ was used as the piezoelectric sensor to achieve a stronger signal. The bottom electrode was made of $10 \mathrm{~mm}$ thick aluminum plate and the top electrode was made of semiconducting polymer film with a similar size as the sensor to achieve a better acoustic match. The pulse used in this experiment was $1 \mathrm{kV}, 1 \mathrm{kHz}$ with $5 \mathrm{~ns}$ width, so the electric field caused by the pulse voltage was about $1 \mathrm{kV} / \mathrm{mm}$ which was much smaller than the applied electric field. Therefore, the impacts caused by the pulse voltage can be ignored in this study.

To clearly describe the space charge dynamics in the samples, three types of the measurement points were utilized, including volts-on, volts-off and decay, as shown in Figure 2. The volts-on measurements were carried out during the HVDC voltage was applied as shown in the red points. After each volts-on measurement, the HVDC voltage was turned off and the volts-off measurement was carried out. When the volts-off measurement was finished, the HVDC voltage was turned on again. 15 seconds were required for each measurement. All the measurements were carried out at the room temperature. For each condition of samples, the whole space charge measurements were repeated 5 times in order to confirm the repeatability of the measurements. The space charge results shown in this paper were the typical results picked from the repeated results.

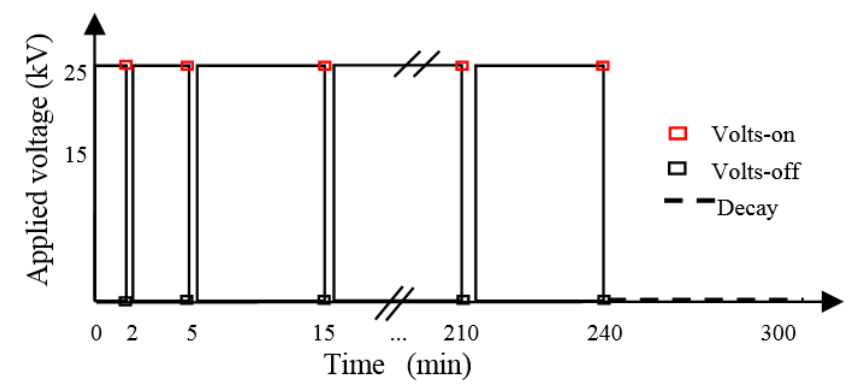

Figure 2. Measurement points in the experiments

\section{SPACE Charge Results}

\subsection{RESULTS OF PRESSBOARD WITH FRESH OIL}

\subsubsection{VOLTS-ON}

The volts-on results of the space charge distributions in the pressboard impregnated with the fresh oil under $+15,+25,-15$ and $-25 \mathrm{kV} / \mathrm{mm}$ are shown in Figure 3. The thin lines with + and - are indicating the positions of anode and cathode.

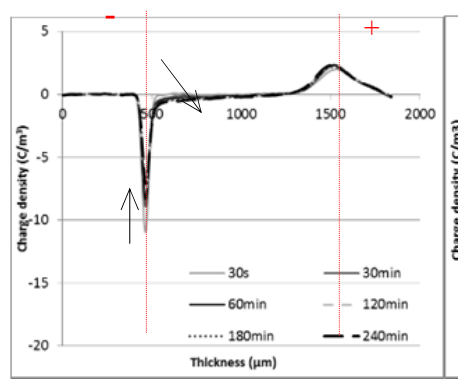

A) $+15 \mathrm{kV} / \mathrm{mm}$

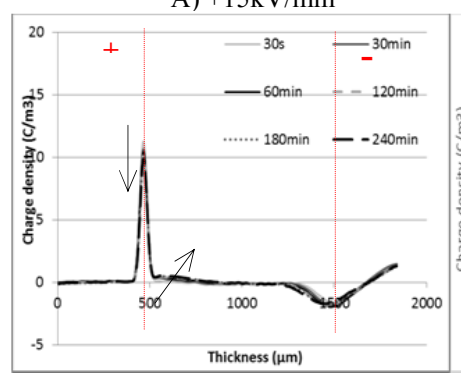

C) $-15 \mathrm{kV} / \mathrm{mm}$

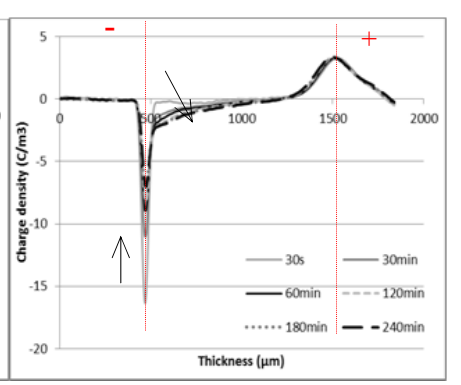

B) $+25 \mathrm{kV} / \mathrm{mm}$

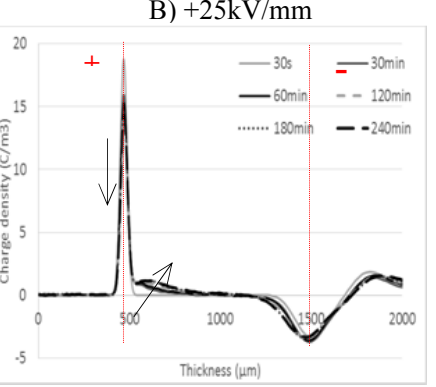

D $-25 \mathrm{kV} / \mathrm{mm}$

Figure 3. Volt-on results of fresh oil samples under different voltages.

All the results above show that the homo-charge injection occurs in the impregnated pressboard since the charge peak at the electrode is decreasing and moving into the insulation 
bulk. Moreover, it can be observed that the higher the applied electric field, the more space charge injected and accumulated in the insulation bulk during the same period.

The plots A) and B) of Figure 3 show the space charge distribution under the positive electric field. When the applied electric field is low, the negative electrode peak is decreasing from about $12 \mathrm{C} / \mathrm{m}^{3}$ at $30 \mathrm{~s}$ to about $7 \mathrm{C} / \mathrm{m}^{3}$ at 3 hours. However, when the applied electric field is higher, the peak is decreasing from about $16 \mathrm{C} / \mathrm{m}^{3}$ to $7 \mathrm{C} / \mathrm{m}^{3}$ during the same period. It is obvious that large amount of negative charge carriers are injected from the cathode to the dielectric bulk. The anode peak is quite stable for both voltages: only a small amount of positive charge carriers are injected from the anode. There are two possible reasons for this observation: first, the charge injection is influenced by the material and the polarity of the electrode, so the charge injection is different for the anode (semiconducting polymer) and the cathode (aluminum); second, there is large acoustic attenuation in the thick impregnated pressboard, so the observation of the charge dynamics at the anode side is not as obvious as the cathode. In this case, the results discussion will mainly focus on the aluminum electrode side.

On the other hand, the plots $\mathrm{C}$ ) and D) of Figure 3 show the space charge distribution under negative electric field. Generally comparing with the results under positive voltages, the space charge distribution is similar, i.e. the charge behavior is almost same, except the difference of the polarity. The anode peak (aluminum) is decreasing from $12 \mathrm{C} / \mathrm{m}^{3}$ at 30 $\mathrm{s}$ to $10 \mathrm{C} / \mathrm{m}^{3}$ after 3 hours under $-15 \mathrm{kV} / \mathrm{mm}$; it is decreasing from $19 \mathrm{C} / \mathrm{m}^{3}$ at $30 \mathrm{~s}$ to $14 \mathrm{C} / \mathrm{m}^{3}$ after 3 hours under -25 $\mathrm{kV} / \mathrm{mm}$. Therefore, the anode peak (aluminum) under negative voltage is larger than the cathode peak (aluminum) under positive voltage at the first $30 \mathrm{~s}$ and also at 3 hours. Moreover, there is smaller peak decrement under negative voltage than positive voltage at the aluminum electrode side. This may indicate the injection of the negative charge carriers is faster than positive charge carriers (or extraction of the negative charge carriers) at the aluminum electrode side.

\subsubsection{VOLTS-OFF}

As shown in Figure 4, space charge distributions under the volts-off condition clearly indicate the accumulated charges in the insulation bulk. When the applied voltage is removed, the accumulated charges locate in the pressboard bulk near the electrodes, which induce the image charges with the different polarity at the two electrodes. With the external voltage application, the accumulated charges are gradually increasing and moving towards to the middle of the pressboard.

From the plots A) and B) of Figure 4, it confirms that homo-charge injection occurs with the positive voltage application. The injected charge carriers are very close to the electrode, accumulating and moving towards to the middle of pressboard with the time. The injected negative charges are accumulated near the cathode in a narrow area: about $54 \mu \mathrm{m}$ from the cathode under $15 \mathrm{kV} / \mathrm{mm}$; and about $63 \mu \mathrm{m}$ from the cathode under $25 \mathrm{kV} / \mathrm{mm}$. At the anode side (semiconducting polymer), the peak of the positive charges is overlapped with the induced negative charge due to the large attenuation and dissipation. Since more and more charge injected and accumulated, more and more induced charges can be observed on the electrode. The induced cathode (aluminum) peak is about $4.8 \mathrm{C} / \mathrm{m}^{3}$ under $+15 \mathrm{kV} / \mathrm{mm}$, and about $11.4 \mathrm{C} / \mathrm{m}^{3}$ under 25 $\mathrm{kV} / \mathrm{mm}$. This can also suggest that the negative charge injection is not linearly proportional to the external electric field, i.e. stronger charge injection occurs under higher electric field.

The plots C) and D) of Figure 4 show the charge injection dynamics under negative voltages. The similar trend can be observed again: homo-charge injected and moved into the pressboard bulk. And moreover, the magnitude of the induced anode (aluminum) peak is generally smaller than the corresponding peaks under positive voltage: about $1.1 \mathrm{C} / \mathrm{m}^{3}$ under $-15 \mathrm{kV} / \mathrm{mm}$ and $7.9 \mathrm{C} / \mathrm{m}^{3}$ under $-25 \mathrm{kV} / \mathrm{mm}$. This is well in agreement with the volts-on results showing that the injection of the positive charge carriers at the aluminum electrode is weaker than the negative charge carriers. And this phenomenon may be caused by either the difference between the two polarities of charge carriers, or the effect of the aluminum electrode.

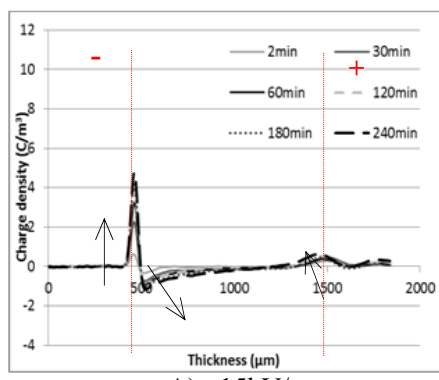

A) $+15 \mathrm{kV} / \mathrm{mm}$

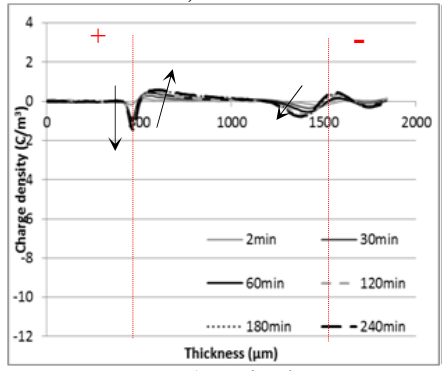

C) $-15 \mathrm{kV} / \mathrm{mm}$

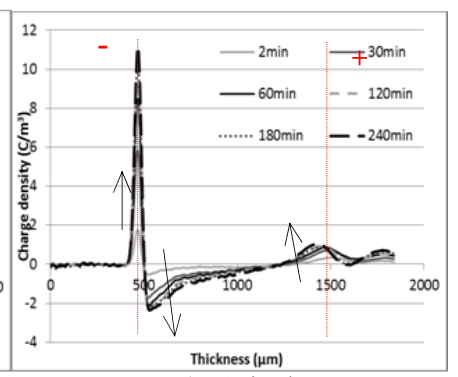

B) $+25 \mathrm{kV} / \mathrm{mm}$

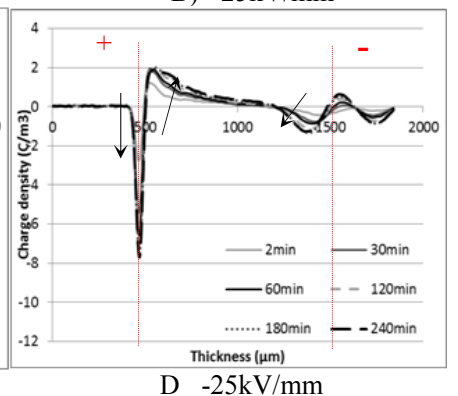

D $-25 \mathrm{kV} / \mathrm{mm}$
Figure 4. Volt-off results of fresh oil sample under different voltages

\subsubsection{DECAY}

The decay tests were carried out after 3 hours voltage stressing. The HVDC voltage was removed, and the charge dynamics can be observed without the effects caused by the external field. The results, shown in Figure 5, indicate the drifting away and recombination behavior of the accumulated charges.

Generally, as shown below in Figure 5, the injected charges decay very slowly, i.e. only very few charges decay during 1 hour time. This indicates the most of injected charge in the case of fresh oil impregnated pressboard are slow moving charges which move very slowly in both volts-on tests and decay tests. For the samples with the same polarity of the applied voltages, the space charge dynamics are mainly affected by the amplitude of the applied voltages, i.e. there are more space charges accumulated in the insulation bulk during the 3 hours stressing time, and also more charges decay during 1 hour distressing time. 

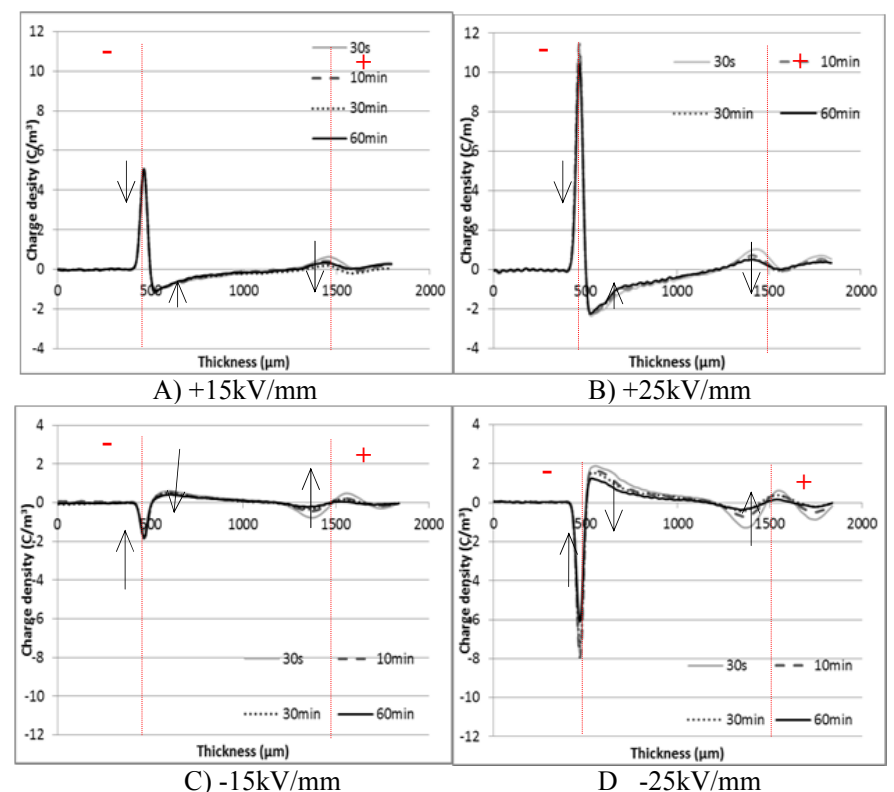

Figure 5. Decay results of fresh oil samples under different voltages.

\subsection{RESULTS OF PRESSBOARD WITH AGED OIL}

\subsubsection{VOLTS-ON}

As comparison, the space charge dynamics in the pressboards impregnated with the service aged oil are also investigated. As shown in Figure 6, the volts-on results of the aged oil samples are very different from those observed from the fresh oil samples.

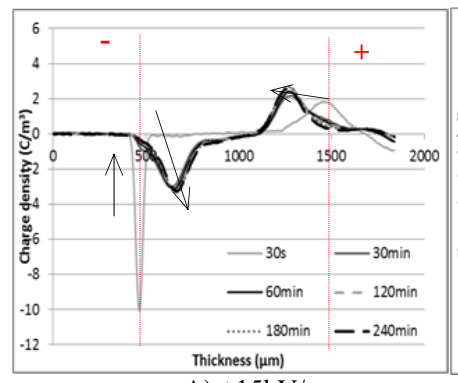

A) $+15 \mathrm{kV} / \mathrm{mm}$

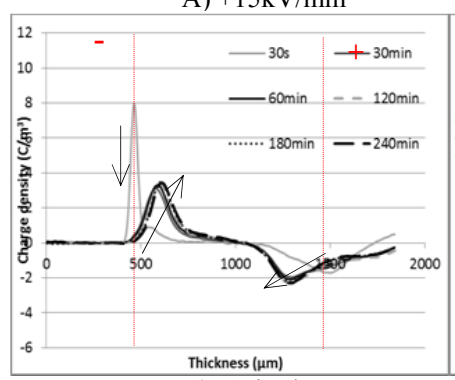

C) $-15 \mathrm{kV} / \mathrm{mm}$

Figure 6. Volt-on results of aged oil samples under different voltages

For the plots A) and B) of Figure 6, under positive voltages, significant amount of homo-charge injection occurs in the aged oil samples: the electrode peaks decrease fast and move towards the dielectric bulk. The cathode (aluminum) peak almost disappears after $30 \mathrm{~min}$, while a negative peak occurs in the insulation bulk near the cathode moving gradually towards to the middle of the pressboard. Similar behavior occurs at the anode (semiconducting polymer), significant positive charges injection can be observed, compared with the fresh oil sample.
This suggests that status of oil can have significant impact on charge dynamics of the pressboard and the service aged oil can greatly enhance the charge injection and its mobility.

Similar to the fresh oil samples, the higher applied electric stress, the more space charge accumulated in the insulation bulk: the amplitude of the injected negative charge peak under 25 $\mathrm{kV} / \mathrm{mm}\left(6 \mathrm{C} / \mathrm{m}^{3}\right)$ is almost the double of $15 \mathrm{kV} / \mathrm{mm}\left(3 \mathrm{C} / \mathrm{m}^{3}\right)$.

For the plots C) and D) of Figure 6, the trend of the space charge behavior is almost the same except the polarity is reversed. The electrode peaks almost disappear and move into the dielectric bulk. Moreover, the amplitude of the injected positive peaks at the anode (aluminum) side is about $3.1 \mathrm{C} / \mathrm{m}^{3}$ under $-15 \mathrm{kV} / \mathrm{mm}$ and $5.9 \mathrm{C} / \mathrm{m}^{3}$ under $-25 \mathrm{kV} / \mathrm{mm}$, which is very close to the results under positive voltages. This may indicate the impact of the polarity of the applied voltage is not significant in the aged oil samples.

\subsubsection{VOLTS-OFF}

The volts-off results, as shown in Figure 7, show the accumulated charges more clearly. During the first $2 \mathrm{~min}$, there have been considerable charges accumulated in the insulation bulk near the electrodes, which suggests the aged oil may bring more fast moving charges than the fresh oil due to the high conductivity. With the voltage application, more accumulated charges are moving towards to the middle.

As shown in the plots A) and B) of Figure 7, there are considerable homo-charges injected and accumulated in the pressboard in the first $2 \mathrm{~min}$. After that, more charge injected into the insulation bulk with the voltage application, therefore, the injected peak is moving towards to the middle of the pressboard. The distance from the injected negative peak to the cathode is related to the applied electric field: with applied voltage for 3 hours, the negative peak is about $165 \mu \mathrm{m}$ from the cathode (aluminum) under $15 \mathrm{kV} / \mathrm{mm}$ and about $186 \mu \mathrm{m}$ under $25 \mathrm{kV} / \mathrm{mm}$. A more significant electric field distortion within the insulation bulk occurs when the more charges with different polarities are accumulated in the middle of the sample.
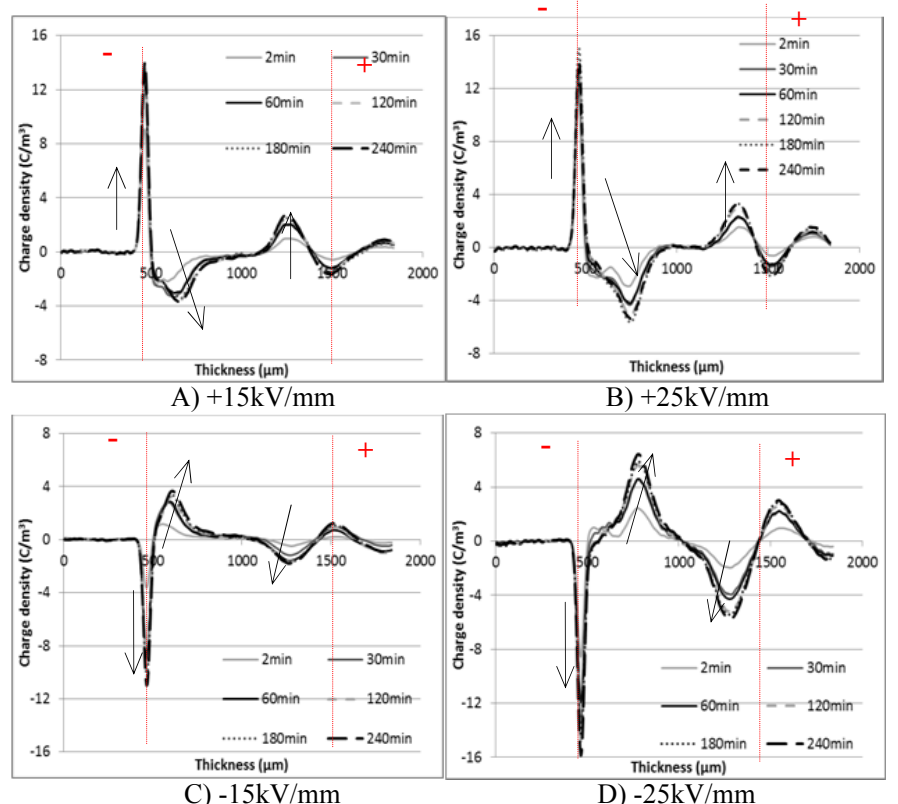

Figure 7. Volt-off results of aged oil samples under different voltages. 
In the plots C) and D) of Figure 7, similarly, space charge injection occurs very quickly when the voltage is applied, indicating the significant effect of the oil property. It also can be observed that the most of space charge are injected in the first $30 \mathrm{~min}$. The injected positive peak from the anode (aluminum) is growing with the stress time, and moving into the insulation bulk with a decreasing speed until reaching a dynamic balance. This dynamic balance seems strongly related to the applied voltage to the sample. For the same pressboard, a gradual peak movement can be observed clearly under low voltage (from about $80 \mu \mathrm{m}$ at $2 \mathrm{~min}$ to about $160 \mu \mathrm{m}$ at 3 hours). On the other hand, under high voltage, the peak moves quickly towards to the middle of the sample within the first 2 min (about $190 \mu \mathrm{m}$ ), and then just slightly move to about $192 \mu \mathrm{m}$ at 3 hours. Compared with the positive voltages, the position of the injected peak is very similar for the same magnitude of the applied voltages. This may suggest that the effect caused by the voltage polarity is much smaller than the magnitude of the voltage in the samples with a similar conductivity.

\subsubsection{DECAY}

Figure 8 shows the decay results for the aged oil samples under different voltages. Generally, the accumulated charges decrease much faster than that from the fresh oil samples. Most of the charges disappear within 30 min, indicating that there are considerable fast moving charges accumulated in the aged oil samples. Thus, the aged oil enhances the dissipation of space charge.

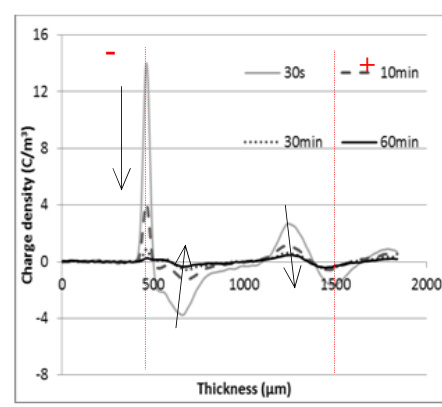

A) $+15 \mathrm{kV} / \mathrm{mm}$

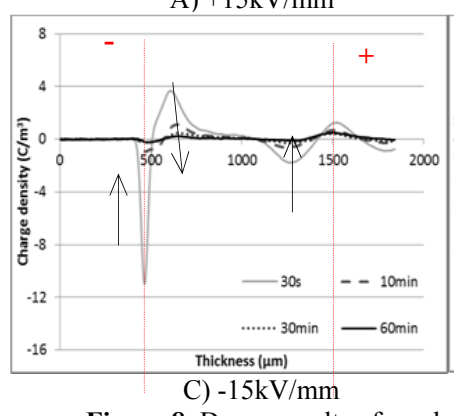

Figure 8. Decay results of aged oil samples under different voltages.

There are two directions for the decay of injected charges: towards electrodes or the middle of the sample, due to the electric field caused by the injected homo-charges. And the movement of the injected peaks is the competition of the two directions. For the samples under lower electric field, the injected peaks near the aluminum electrode are slightly moving to the middle of the sample with the decay time, which may suggest more charges are dissipated from the electrode. In contrast, under higher electric field, the peaks are slightly moving to the electrode side with decay time, which may suggest more charges move towards the middle of the pressboard attracted by the injected charges with opposite polarity, due to the space charges accumulated deeper in the pressboard under higher electric field.

\section{ANALYSIS AND DISCUSSION 4.1 TOTAL ABSOLUTE CHARGE AMOUNT}

To have a better understanding of the impact of the oil property on the space charge formation and movement, the total absolute charge amount for each sample is calculated by the equation:

$$
Q(t)=\int_{0}^{d}|\rho(x, t)| S d x
$$

where $\mathrm{d}$ is the thickness of the sample, $\rho(\mathrm{x}, \mathrm{t})$ is the charge density, $\mathrm{S}$ is the area of the electrode. Therefore, the total absolute amount of space charge for each sample can be calculated based on the PEA results above, as shown in Figure 9.

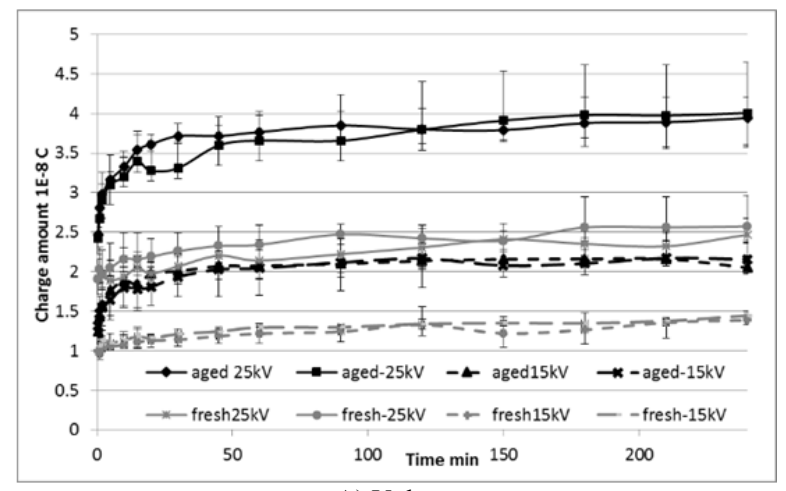

A) Volt-on

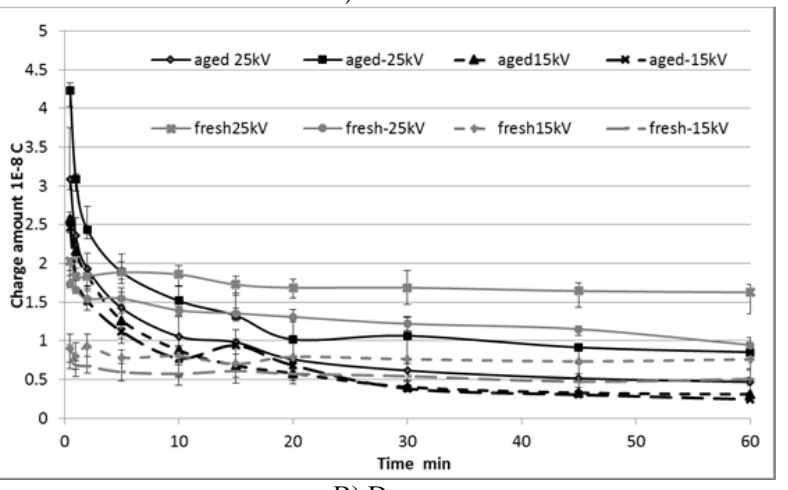

B) Decay

Figure 9. Absolute charge amount in the thick pressboard

The total charge amount during the volts-on process (plot A) shows three levels of charge accumulation in the samples: there is the largest charge amount in the aged oil sample under $\pm 25 \mathrm{kV} / \mathrm{mm}$; the aged oil sample under $\pm 15 \mathrm{kV} / \mathrm{mm}$ and the fresh oil sample under $\pm 25 \mathrm{kV} / \mathrm{mm}$ are at the middle level; and the fresh oil sample under $\pm 15 \mathrm{kV} / \mathrm{mm}$ accumulates the least space charge. Moreover, the same applied stress results in a similar start point in the two types of oil samples, e.g. the charge amount of the samples under $\pm 25 \mathrm{kV} / \mathrm{mm}$ and \pm 15 
$\mathrm{kV} / \mathrm{mm}$ are similar when the stressing time is short. However, the charge amounts of the aged oil samples dramatically increase in the first $20 \mathrm{~min}$ and then become stable. On the other hand, the charge amounts of the fresh oil samples are generally stable, with gradually increasing during a much longer period.

The total charge amount in the decay process shows that the charges accumulated move fast in the aged oil samples, resulting in significant reduction in the first $10 \mathrm{~min}$; however, in the fresh oil samples, most of space charges are slow moving charges which decreases gradually over 1 hour time. It can be seen, after $20 \mathrm{~min}$, large amount of space charges still remain in the fresh oil samples, while only little charges are in the aged oil samples.

\subsection{ELECTRIC FIELD DISTORTION}

One of the major impacts of space charge accumulation is the distortion of the local electric field distribution in the dielectric bulk. The injected homo-charge can reduce the electric field in the region between electrodes and sample. However, with the charges moving deeper towards to the middle of the pressboard, the electric field is gradually increasing in the middle of the insulation bulk. The electric field distributed along the sample can be calculated based on the charge density from the PEA results:

$$
E(x)=\int_{0}^{x} \frac{\rho(x)}{\varepsilon_{0} \varepsilon_{r}} \mathrm{~d} x \quad 0 \leq x \leq d
$$

where $\rho(x)$ is the charge density, $\varepsilon_{0}$ is the vacuum permittivity, $\varepsilon_{\mathrm{r}}$ is the relative permittivity of test sample, $d$ is the thickness of the sample.

Therefore, the distortion factor of the electric field $\Delta \mathrm{E}$ can be calculated by the equation:

$$
\Delta E=\frac{E_{\max }-E_{a v}}{E_{a v}} \times 100 \%
$$

where the $E_{\max }$ is the maximum value of the electric stress in the dielectric bulk due to the space charge accumulation; $E_{a v}$ is the average value of the applied electric stress.

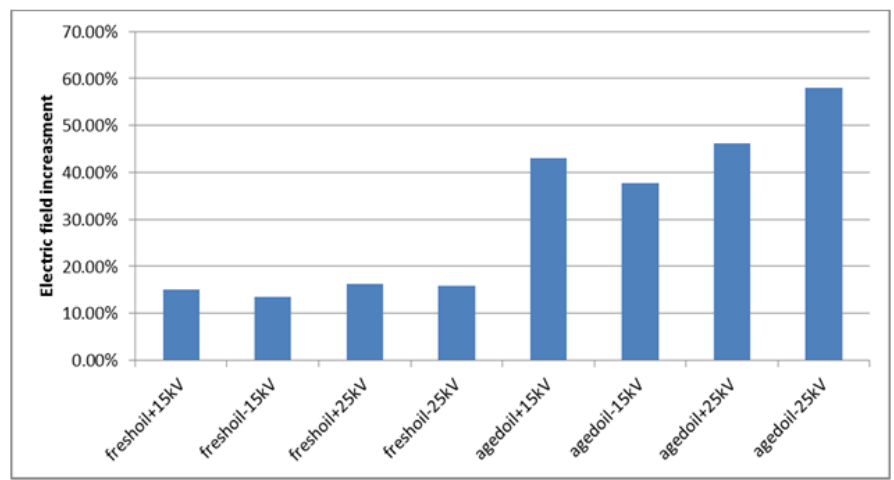

Figure 10. Electric field enhancements for the different conditions.

The results, as shown in Figure 10, indicate that both the polarity and magnitude of the applied electric stress, and the oil status can affect the electric field distortion in the impregnated pressboard. The oil property is the dominant factor in this experiment: the field enhancement due to charge is around $15 \%$ for fresh oil and $50 \%$ for aged oil. Moreover, the higher applied electric field related to a larger electric field (usually about $2 \%$ difference in the fresh oil samples and 5\% in the aged oil samples); the positive voltage usually leads to larger electric field distortion (about 2\% difference in the fresh oil samples and $7 \%$ in the aged oil samples). However, due to the large conductivity and much more complex status of the aged oil sample, the results usually vary in a relative larger range. In addition, the calculated electric field is probably a little smaller than the real value as the attenuation in the space charge measurement is not considered here.

\subsection{TRAP ENERGY DISTRIBUTION}

In the trap theory, the space charge distribution is strongly related to the trap energy distribution in the sample. This method is first developed by Simmons et al [10] in the isothermal current decay theory (ICD). After that, Tu. et al applied the method to measure energy distribution of surface trap [11-13]. In 2011, Tang et al successfully estimated the trap energy distribution in oil-paper insulation based on the PEA results [14], which established the relationship between trap depth and charge depolarization. The method can be explained as follows:

The trapped charges decay following an approximate exponential trend in surface potential decay [14], which can be expressed as:

$$
\sigma=A e^{-t / \tau}
$$

Where $\sigma$ is the equivalent surface charge density; $\mathrm{A}$ is the initial surface charge density; $\tau$ is the time constant of decay. The variation law of the current density including the constant of decay time can be obtained by:

$$
|j(t)|=\frac{r^{\prime}}{L} \frac{A}{\tau} e^{-t / \tau}
$$

Where $\mathrm{r}^{\prime}$ is the average centroid of the charge; $\mathrm{L}$ is thickness of the samples.

When the sample is short circuited, the trapped surface charge will drift away from the electrode following that the shallow trapped charges release first and then the deep trapped charges. If the released charges will not re-trap again, the relationship of trap energy level $E_{t}$, the depolarization current $j$ and the trap density $\mathrm{N}\left(\mathrm{E}_{\mathrm{t}}\right)$ can be calculated by:

$$
\begin{gathered}
E_{t}=k T \ln (v t) \\
j=\frac{q L k T}{2 t} f_{0}\left(E_{t}\right) N\left(E_{t}\right)
\end{gathered}
$$

Where $f_{0}\left(E_{t}\right)$ represents the original occupation rate of the traps inside the dielectrics; $\mathrm{q}$ is the electron charge; $\mathrm{k}$ is the Boltzmann constant; $\mathrm{T}$ is the absolute temperature; $\mathrm{v}$ is the frequency of electron vibration. The trap energy of electron is calculated from the bottom of the conduction band, and the trap energy of hole is calculated from the peak of the valence band.

$$
\text { If we define } C_{1}=\frac{q L k T}{2} f_{0}\left(E_{t}\right), C_{2}=\frac{r^{\prime} A}{L}, \mathrm{C}_{1} \text { and } \mathrm{C}_{2}
$$

are constant, then

$$
N\left(E_{t}\right)=\frac{C_{2}}{C_{1}} \frac{t}{\tau} e^{-t / \tau}
$$


Therefore, the density of trap energy level can be decided by the decay constant of charge density and decay time, which can be obtained from the PEA results.

As shown in Figure 11, it clearly indicates the difference between two kinds of samples (red lines indicate aged oil samples; blue lines indicate fresh oil samples): the energy level of fresh oil samples is mainly distributed in the range of 0.9 to $0.94 \mathrm{eV}$, and the trap density is lower from about $1 \times$ $10^{13} \mathrm{~m}^{-3} \mathrm{eV}^{-1}$ to $3 \times 10^{13} \mathrm{~m}^{-3} \mathrm{eV}^{-1}$. It can be observed that there are still amount of traps with the energy level higher than 0.95 $\mathrm{eV}$; for the aged oil samples, the energy level is mainly distributed in the range of 0.86 to $0.92 \mathrm{eV}$ with a much higher trap density from about $5 \times 10^{13} \mathrm{~m}^{-3} \mathrm{eV}^{-1}$ to $6.5 \times 10^{13} \mathrm{~m}^{-3} \mathrm{eV}^{-1}$. It can be also observed that the maximum trap density is larger under higher electric field, which may suggest that the amplitude of the applied voltage can affect the trap density in the impregnated pressboard. However, this trend is not very suitable for the aged oil samples as the space charge have been deeply injected into the insulation bulk, therefore, the assumption of this method may be not very suitable in this case: there are considerable charges that are not dissipated from the electrodes but recombined in the middle of the pressboard, so the depolarization current calculation may be not accurate; there may have amount of space charge retrapped in the pressboard during the de-trap process as the pressboard samples are very thick and the space charge distribution is deeply into the insulation bulk. In this case, this method is not suitable for the thick samples with strong space charge injection. However, it still can clearly show the great difference between two kinds of samples in this work.

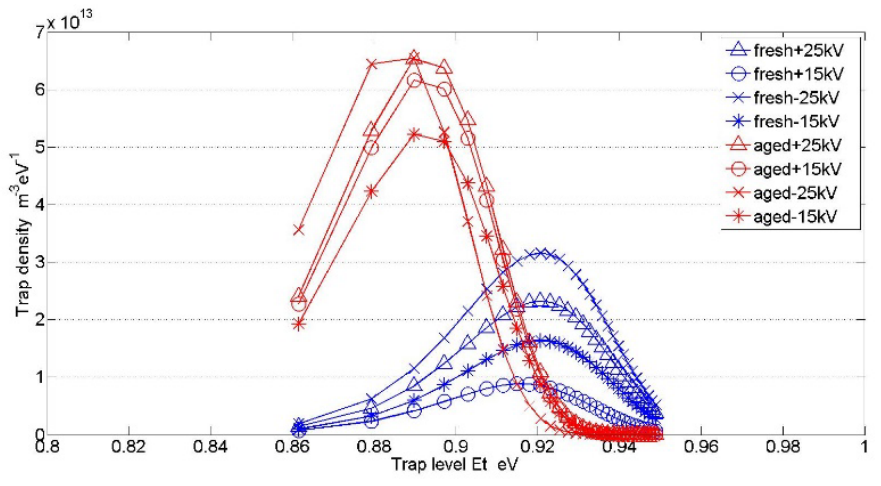

Figure 11. Results of the trap energy distribution.

\subsection{APPARENT CHARGE MOBILITY}

Another important parameter that can be used to represent the charge behavior and the characteristic of the dielectric material is the apparent charge mobility [15, 16]. It is usually obtained based on the decay results with less external stress impacts. Usually, the charge mobility $\mu$ can be represented as

$$
\mu=v / E
$$

where $v$ is the velocity of charge injected from electrodes to the dielectrics and the $\mathrm{E}$ is the applied electric field.

Based on the assumptions of 1) recombination can be neglected, 2) the relationship between charge depolarization time and trap depth (the charges stored in the deep traps moving slower), 3) charge densities are replaced by their average values, and 4) the prevailing charge is unipolar and located close to electrodes, the apparent charge mobility $\mu(t)$ can be simply but severely approximately obtained from the depolarization process by the following equation:

$$
\mu(t)=\frac{2 \varepsilon}{q(t)^{2}} \frac{\mathrm{d} q(t)}{\mathrm{d} t}
$$

where $q(t)$ is the mean charge density through the thickness of the material; $\varepsilon$ is the dielectric permittivity; $t$ is the depolarization time.

This equation (10) can describe the information about the deep trap behaviour in the insulation due to the PEA measurement operations for starting decay test, which is usually about several seconds.

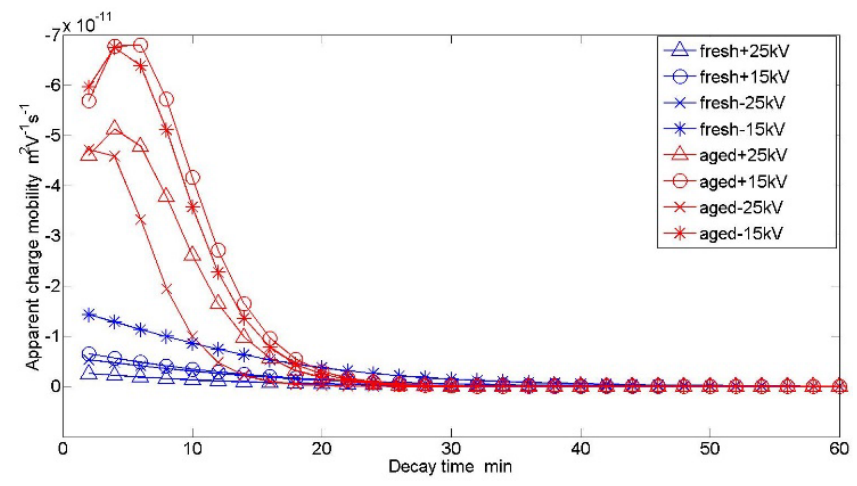

Figure 12. Results of the apparent charge mobility.

The comparison of the apparent charge mobility for different samples is described in Figure 12. The great mobility difference between the samples with two oil characteristics can be observed, which again indicates the significant impacts of the oil property on the charge dynamics of the impregnated pressboard insulation system. Generally, the charge mobility in the aged oil samples (red lines) is much higher than in the fresh oil samples (blue lines). The injected charges moves fast in the first 30mins in the fresh samples, and then gradually decrease. On the contrary, in the aged oil samples, the apparent charge mobility is very large in the first $20 \mathrm{mins}$ (with more than $5 \times 10^{-11} \mathrm{~m}^{2} \mathrm{~V}^{-1} \mathrm{~s}^{-1}$ ), and then dramatically drops to below $0.1 \times 10^{-11} \mathrm{~m}^{2} \mathrm{~V}^{-1} \mathrm{~s}^{-1}$. This results also agrees well with the results of the trap depth that most of the traps in the aged oil are shallow traps, so the charge mobility in the aged oil are much larger than the fresh oil samples.

Although this method can clearly describe the dielectric properties in the two groups of samples, however, the charge mobility curves of the aged oil samples show a quick increasing in the first 7 mins. This may be caused by the limitation of this calculation method. The recombination (or net charge) of the space charge cannot be ignored in this case as they are deeply injected in the insulation bulk. In other words, there are considerable charges located in the middle of the sample are recombined when the depolarization occurs, which will affect the calculation of the charge mobility.

\section{CONCLUSION}

The present work is concentrated on the space charge dynamics in the $1 \mathrm{~mm}$ thick impregnated pressboard by the means of the PEA method. The influence of the applied electric stress and oil status on charge dynamics in pressboard 
has been investigated. The total charge amount and the distortion of the electric field are also analyzed based on the PEA results.

It has been observed that homo-charge injection in the all samples; the higher applied stress, the more space charge accumulated in the insulation bulk; the service aged oil can greatly enhance the charge injection and mobility, e.g. significant fast moving charges are accumulated in the sample, resulting in a severe electric field distortion in the middle of the pressboard.

The electric field distortion caused by the space charge accumulation is calculated based on the space charge distribution results. In the fresh oil samples, the distortion is about 14 to $16 \%$; while in the aged oil samples, the distortion varies from 38 to $58 \%$. The magnitude and polarity of the applied voltage can also affect the field distortion. However, the property of the oil is the major factor in this work.

The trap depths in the samples with different oil status show considerably difference: the energy level of the fresh oil samples mainly distribute in the range of 0.9 to $0.94 \mathrm{eV}$ with a smaller trap density. On the contrary, the energy level of the aged oil samples is focused on the range of 0.86 to $0.92 \mathrm{eV}$ with much higher trap density. This result indicates there are more space charge in the aged oil samples and most of them are fast moving charges; much less charges injected in the fresh oil samples and most of them are slow moving charges, which is also confirmed by the calculation of the apparent charge mobility in all the samples. Moreover, the results also show the limitation of the calculation method of the trap energy and charge mobility in the thick samples, especially in the aged oil samples (the space charge recombination cannot be ignored).

\section{ACKNOWLEDGMENT}

The authors are grateful to the National Grid for their financial support.

\section{REFERENCES}

[1] X. Wu, G. Chen, A. E. Davies, Y. Tanaka, S. J. Sutton and S. G. Swingier, "Space charge measurements in polyethylene under DC and AC operating conditions using the PEA technique," 8th Int'l. Conf. Dielectric Materials, Measurements and Applications, (IEE Conf. Publ. No. 473), pp. 57-62, 2000.

[2] J. Hao, G. Chen and R. Liao, "Effect of thermally aged oil on space charge dynamics in oil/paper insulation system," Joint Colloquium on Transformers, Materials and Emerging Test Techniques, Kyoto, Japan, 2011.

[3] N. Hozumi, T. Takeda, H. Suzuki and T. Okamoto, "Space charge behaviour in XLPE cable insulation under 0.2-1.2 MV/cm dc fields," IEEE Trans. Dielectr. Electri. Insul., Vol. 5, pp. 82-90, 1998.

[4] C. Tang, G. Chen, M. Fu and R. Liao, "Space charge behaviour in multilayer oil-paper insulation under different DC voltages and temperatures," IEEE Trans. Dielectr. Electr. Insul., Vol. 17, no. 3, pp. 778-788, 2010.

[5] J. Hao, G. Chen, R. Liao, L. Yang and C. Tang, "Infulence of moisture on space charge dynamics in multilayer oil-paper insulation," IEEE Trans. Dielectr. Electr. Insul., Vol. 19, no. 4, pp. 1456-1464, 2012.

[6] M. Jeroense and P. Morshuis, "Space charge measurements on impregnated paper: a review of the PEA method and a disscussion of results," IEEE Electrical Insulation Magazine, Vol. 13, No. 3, pp. 26-35, 1997.

[7] R. Ciobanu, I. Prisecaru and C. Schreiner, "Space charge evolution in thermally aged celluloe materials," IEEE Conf. Solid Dielectr. (ICSD), Taulorw, France, Vol.1, pp. 221-224, 2004.
[8] Y. Zhou, Y. Wang, G. Li, N. Wang, Y. Liu, B. Li, P. Li and H. Cheng, "Space charge phenomena in oil-paper insulation materials under high voltage direct current," J. Electrostatics, Vol. 67, pp. 417-421, 2009.

[9] R. Liu and A. Jaksts, "Moisture and space charge in oil-impregnated pressboard under HVDC," IEEE Int'l. Conf. Conductuion Breakdown Solid Dielectr., pp. 17-22, 1998.

[10] J. G. Simmons and M. C. Tam, "Theory of isothermal currents and the direct determination of trap parameters in semiconductors and insulators containing arbitrary trap distributions," Phys. Rev. B, Vol. 7, No. 8, pp. 3706-3713, 1973.

[11] Y. Zhang, B. Yang and D. Tu, "Measuring distribution of carrier trap energy state density at interface of dielectric with step pressure wave method," IEEE Conf. Electr. Insul. Dielectr. Phenomena (CEIDP), USA, pp. 303-308, 1989.

[12] W. Shen, H. Mu, G. Zhang, J. Deng and D. Tu, "Identification of electron and hole trap based on isothermal surface potential," J. Appl. Phys., Vol. 083706, No. 113, 2013.

[13] X. Wang, S. Chen, X. Cheng and D. Tu, "Measuring Energy Distribution of Surface Trap in Polymer Insulation by PEA Method," Chinese Soc. Electr. Eng. (CSEE), Vol. 29, No. 1, pp. 127-132, 2009 (in Chinese).

[14] C. Tang, R. Liao, G. Chen and L. Yang, "Research on the feature extraction of DC space charge behaviour of oil-paper insulation," Science China Techological Sci., Vol. 54, No. 5, pp. 1315-1324, 2011 (in Chinese.

[15] J. M. Alison, G. Mazzanti, G. C. Montanari and F. Palmieri, "Mobility estimation in polymeric insulation through space charge profiles derived by PEA measurements," IEEE Conf. Electr. Insul. Dielectr. Phenomena (CEIDP), 2002.

[16] G. C. Montanari, "Dielectric material properties investigated through space charge measurements," IEEE Trans. Dielectr. Electr. Insul., Vol. 11, No. 1, pp. 56-64, 2004.

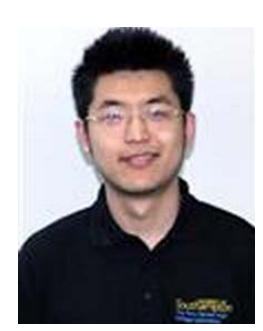

Miao Hao was born in China in 1987. He received his B.Eng. degree (2009) from Xi'an Jiaotong University, China and M.Sc. degree (2011) from University of Southampton, UK in electrical engineering. Since 2011, he has been a Ph.D. student in the University of Southampton, UK. His main research interests include space charge and ageing mechanism in the oil impregnated pressboard insulation system for HVDC converter transformer.

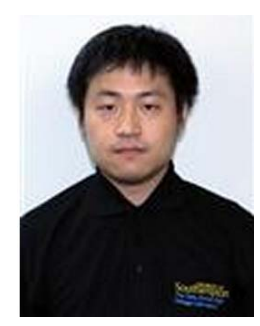

Yuan Zhou was born in China in 1987. He received his B.Eng. degree in electrical engineering from Xi'an Jiaotong University, China, in 2009. Since 2011, he has been a Ph.D. degree student in the University of Southampton, UK. His main research interests include electrical conduction and space charge in the oil impregnated pressboard.

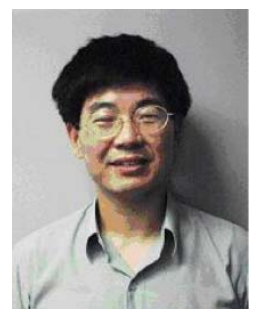

George Chen (SM'11) was born in China in 1961. He received the B.Eng. (1983) and M.Sc. (1986) degrees in electrical engineering from Xi'an Jiaotong University, China. After he obtained the Ph.D. degree (1990) from the University of Strathclyde, UK, on the work of permanent changes in electrical properties of irradiated low-density polyethylene, he joined the University of Southampton as postdoctoral research fellow and became a senior research fellow subsequently. In 1997 he was appointed as a research lecturer and promoted to a Reader in 2002. He is now a professor of high voltage engineering at the University of Southampton and a visiting professor of Xi'an Jiaotong University. Over the years, he has developed a wide range of interests in high voltage engineering and electrical properties of materials and published over 300 papers. He is active in the HVDC systems and involved with technical working groups in both IEEE and CIGRE. 


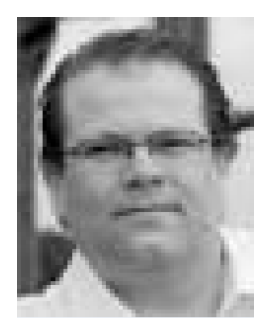

Gordon Wilson completed his chemistry degree at the University of Surrey in 1995. This was followed by a National Grid-sponsored Ph.D. degree in characterizing mineral transformer oil, also at the University of Surrey. He joined National Grid in 1999 as an oil chemist providing support to a team of transformer specialists. Since 2007 he has worked on transformer thermal ratings whilst retaining responsibility for transformer oil issues. Gordon is a member of the BSi National Committee for electrotechnical fluids, he is the UK regular member for CIGRE Study Committee on materials.

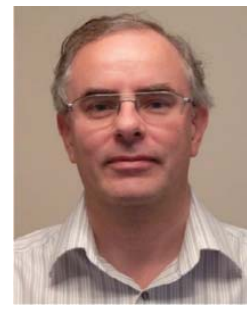

Paul Jarman was born in London on 27 September 1962, and graduated from Cambridge University in 1984 with an Honours degree in electrical science. He joined the Central Electricity Generating Board, Research Division, working on, amongst other projects, FRA testing of transformers. In 1990, he joined the National Grid as a transformer engineer, becoming head of transformers in 1998. Since 2001, Jarman has been National Grid's technical specialist for transformers now within the Asset Management group. Jarman is chairman of IEC TC14, the international committee for power transformer standards; is the UK regular member of CIGRE study committee A2 for transformers; and has recently been the convenor of a CIGRE group on transformer monitoring. He is a chartered electrical engineer and member of the IET. 